\title{
An Interview with Tyler Kloefkorn
}

\section{Scott Hershberger}

In September, Tyler Kloefkorn joined the AMS staff as Associate Director of Government Relations. In this role, Kloefkorn oversees the AMS education policy portfolio, with a focus on undergraduate and graduate education in the mathematical sciences. Before coming to the AMS, he was a senior program officer for the Board on Mathematical Sciences and Analytics and the director for the Committee on Applied and Theoretical Statistics at the National Academies of Sciences, Engineering, and Medicine. Previously, Kloefkorn spent a year and a half as a Science and Technology Policy Fellow through the American Association for the Advancement of Science, working on data science at the National Science Foundation's Directorate for Computer and Information Science and Engineering. AMS writer Scott Hershberger spoke with Kloefkorn in July 2021. An edited version of that interview follows.

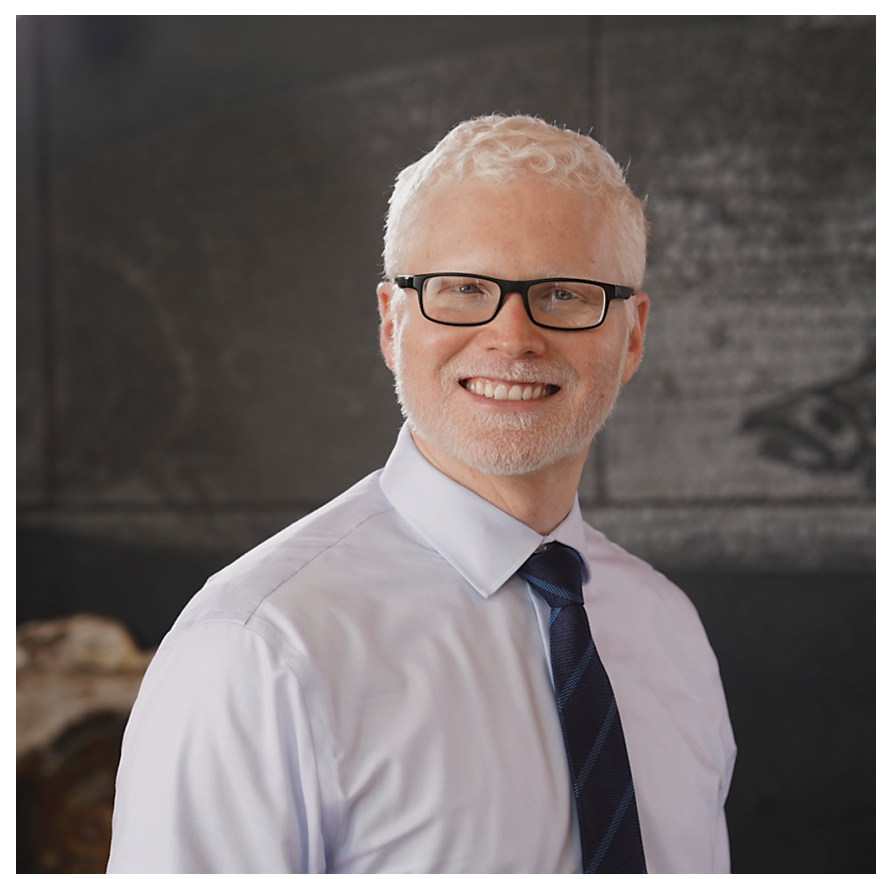

Tyler Kloefkorn, AMS Associate Director of Government Relations

Scott Hershberger is the communications and outreach content specialist at the AMS. His email address is s1h@ams.org.

For permission to reprint this article, please contact: reprint-permission aams.org.

DOI: https://dx.doi.org/10.1090/noti 2375
Notices: Let's start with your educational journey in math. What drew you to policy and advocacy work?

Kloefkorn: I went to a small liberal arts school, Whittier College in California, for my undergrad degree. I got an excellent mathematics education and was also exposed to some of the broader connections that we make with mathematics in the sciences, in engineering, and in policy. That stuck through the rest of my education. I went on to the University of Oregon and got my PhD there in noncommutative and homological algebra. Throughout my time in Oregon, I was very active in policy at the university level and at the department level, advocating for mathematicians both to the university and to the broader community in Eugene. I always had a good appetite for policy work in the mathematical sciences, and that's what led me later on in my career to take the AAAS Science and Technology Policy Fellowship here in DC. That solidified my enjoyment and desire to work on behalf of the mathematics community.

Notices: What have you learned from interacting with public funding mechanisms as both a sponsor and an awardee?

Kloefkorn: On the side of the mathematics community seeking funding, I like the thrill of coming up with a novel idea. It's super fun and intellectually interesting to work in that space and do something that no one else is doing. 
When I was at the National Science Foundation on the sponsor side of things, I got a taste for the big picture. I especially got to see what other communities were doing that was relevant to the mathematical sciences. For example, I got deeply exposed to the world of data science. That was really important for understanding STEM community trends and where mathematics can play a role. Seeing both sides of that-representing the mathematics community, and then being aware of what the mathematics community needs to think about that they may not be thinking aboutis incredibly important for having a broad perspective on research and education.

Notices: What has your biggest takeaway been from your time at the National Academies that you will bring to the AMS?

Kloefkorn: I have taken from it that the mathematics community should be a little more involved in reaching out and making connections to other areas. Research and education in the mathematical sciences are embedded in so many things. I'm not saying that mathematics is everything and everything boils down to mathematics-but I think there's connections that we can make as mathematicians that will help advance research and education across STEM fields.

Notices: What are some highlights from your professional career so far, things that you've especially enjoyed doing?

Kloefkorn: Highlight number one would be working on a project that I'm doing right now at the National Academies called "Illustrating the Impacts of the Mathematical Sciences." This project is unique because we're coming up with one-page graphics that show how mathematics has impacted a particular sector or a particular science or technology. Coming up with those stories where math has been impactful has been both fun and challenging, and I've thoroughly enjoyed that work.

Highlight number two: It's not one specific thing, but I have immensely enjoyed the mathematical sciences network, getting the opportunity not only to work with AMS, but also MAA, SIAM, and ASA. Seeing that broader ecosystem has been super fun.

Notices: Can you talk about your involvement and interactions with the AMS over the years?

Kloefkorn: I grew up with AMS. I went to section meetings, I went to JMM, I was actively reading Notices. Once I got into policy work, I started working more with [AMS Director of Government Relations] Karen Saxe and her office in DC. I mentioned how, in my work at the National Academies, we often look to see how math plays a role in a particular topic area. Sometimes we just needed some assistance in understanding how math played that role. We would reach out to Karen's office and say, "Hey, Karen, help us. Do you know a mathematician who does this?" and she's like, "Got it," and sends us 10 names. The AMS has been such a good resource for us at the Board on Mathematical Sciences and Analytics.

Notices: What are you looking forward to most in your new role?

Kloefkorn: I'm exceptionally humbled to be representing the members and working on their behalf. I'm looking forward to hearing what the community needs and wants with regard to policy, in the context of research and education trends, and then advocating for it. I want to work for the members and do the best I can in representing them here in DC.

I'm very much looking forward to continuing to work with other societies, building a network of people here in DC, and getting to know people who are also helping to advance the mathematical sciences, both in research and education. And I'm excited to be reaching out to members themselves, especially with regard to education.

I'll also be the staff liaison to the AMS Committee on Education. I know many of the current members and have worked with them in the past. I'm excited to work with those members again in this capacity and meet some of the other members who I haven't worked with. This is a policy committee that has a lot of sway with the AMS and with the community. If they have something to say with regard to what we should be doing in education, it's going to be heard loudly. I'm very much looking forward to shepherding those voices and helping them, frankly, be as loud as possible. They have this megaphone, and they need to use it. It's my job to broadcast what they want to do.

Notices: What are the key issues and trends that you're looking to address in your new role?

Kloefkorn: I am really interested in diversity, equity, and inclusiveness in our graduate programs in the mathematical sciences. It's an incredibly important issue that I hope to advance, and I know the AMS does too. Diversity, equity, and inclusiveness in our graduate programs are paramount for our success moving education in the mathematical sciences forward, and we need to improve in these areas.

Also, I am intrigued by what's going on with funding for basic research in the sciences-NSF funding, what the new proposed Directorate ${ }^{1}$ will look like, what new money flows into research, and thinking about how mathematics can play a role. A lot of the proposed new funding is going to go towards technology and data science. There's a

\footnotetext{
${ }^{1}$ The "Directorate for Technology, Innovation, and Partnerships" was included in President Biden's budget proposal for fiscal year 2022 and has also been proposed in legislation in both chambers of Congress.
} 
plethora of things that are on the table, but I think it'll be cool to work on behalf of the mathematics community in that space and say, "Hey, this is something that the mathematics community can contribute to and will have tremendous impact."

Notices: What has stood out to you with regard to the impact of the pandemic on mathematics education?

Kloefkorn: I have been quite impressed with the work of Abbe Herzig, who's been working in this space. ${ }^{2}$ I think she's done a great job of hearing the community and what it needs in terms of education during the pandemic. I think there are a lot of opportunities to take what she's done and build upon it, both advocating for educators and advocating for students in this new world-what should mathematics education look like? I know for educators there's so much that's changed in terms of assessments, in terms of curriculum, whether it's hybrid or fully in-person or fully virtual. And then, in terms of students, I think there's a lot to be done in evaluating what we want to keep from our old model of educating and what we might want to change. What's best online, and what's best done in person? I think we have a lot to learn.

Notices: Is there anything you wish policymakers understood better about mathematics or mathematics education?

Kloefkorn: I often wish policymakers had a better understanding of the timeline for the impact of mathematics research. I wish that there was a bit more appreciation for how mathematics done 100 years ago impacts us today, and why we should continue doing basic research in the mathematical sciences, even if it's not going to be strictly applied today. That's not just pure mathematics-that's applied mathematics, that's statistics, I'm talking about mathematical research of all kinds. I wish there was a better understanding that maybe we won't see the impact of this math research today, maybe we won't see it in five years, but we'll probably start seeing it tens of years later.

For education, I would like policymakers to have a deeper understanding of why math education matters and be a little bit more in tune with how exceptionally talented and smart the people who receive math degrees are. Sometimes it's difficult for mathematicians to market themselves to potential employers because they don't have specific, let's say, coding training, or they don't have specific training in a lab science. I think policymakers often don't appreciate just how versatile a mathematician is and how many sectors they could contribute to, even if they don't have specialized training.

\footnotetext{
${ }^{2}$ Prior to Kloefkorn's hiring, Abbe Herzig was AMS Director of Education.
}

Notices: What do you enjoy doing outside of mathematics and work?

Kloefkorn: I really like cycling. I just love the independence of biking. I thoroughly enjoy being able to go for an escape and go for a longer ride, and the ability to get on my bike and go get groceries or get food somewhere. And I like exercising in general, whether it's running or anything active.

I also do pottery, though I stopped for a little while with the pandemic. There's a studio here in Virginia where I learned how to use a pottery wheel and make things like mugs and bowls. When you get good, then you can build bigger and more complicated things like vases or pitchers. To me it's very mathy-it's all about surfaces of revolution.

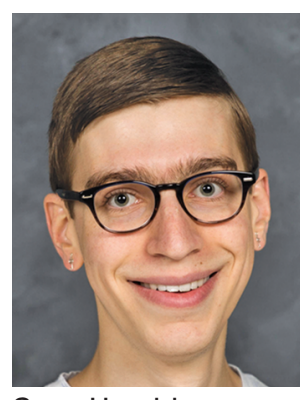

Scott Hershberger

\section{Credits}

Photo of Tyler Kloefkorn is courtesy of Tyler Kloefkorn. Author photo is courtesy of Jiyoon Kang. 